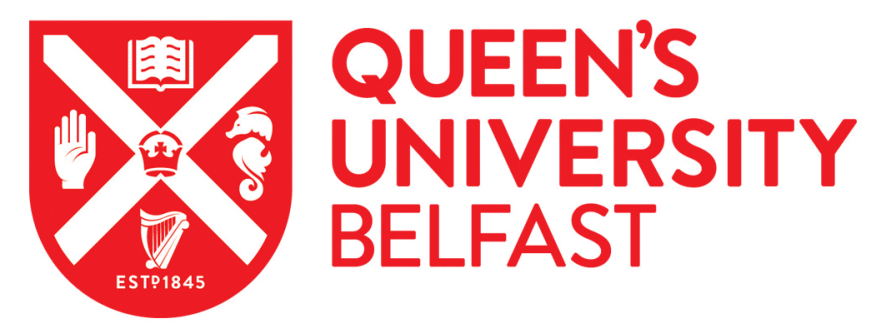

\title{
Long-term outcome of patients operated with pars plana vitrectomy for primary rhegmatogenous retinal detachment.
}

Peto, T., Poulsen , C. D., Green , A., \& Grauslund , J. (2019). Long-term outcome of patients operated with pars plana vitrectomy for primary rhegmatogenous retinal detachment. Ophthalmic Research.

https://doi.org/10.1159/000499130

Published in:

Ophthalmic Research

Document Version:

Peer reviewed version

Queen's University Belfast - Research Portal:

Link to publication record in Queen's University Belfast Research Portal

Publisher rights

Copyright 2019 Karger Publishers. This work is made available online in accordance with the publisher's policies. Please refer to any applicable terms of use of the publisher.

\section{General rights}

Copyright for the publications made accessible via the Queen's University Belfast Research Portal is retained by the author(s) and / or other copyright owners and it is a condition of accessing these publications that users recognise and abide by the legal requirements associated with these rights.

Take down policy

The Research Portal is Queen's institutional repository that provides access to Queen's research output. Every effort has been made to ensure that content in the Research Portal does not infringe any person's rights, or applicable UK laws. If you discover content in the Research Portal that you believe breaches copyright or violates any law, please contact openaccess@qub.ac.uk. 


\section{Title:}

Long-term outcome of patients operated with pars plana vitrectomy for primary rhegmatogenous retinal detachment.

\section{Short title:}

Thirty months outcome in rhegmatogenous retinal detachment

\section{Authors:}

Christina D. Poulsen ${ }^{1,2,3}$, Anders Green ${ }^{2,3}$, Jakob Grauslund ${ }^{1,2}$, Tunde Peto ${ }^{2,4}$

1. Department of Ophthalmology, Odense University Hospital, Sdr. Boulevard 29, Odense, Denmark

2. Department of Clinical Research, University of Southern Denmark, Odense, Denmark

3. OPEN, Odense Patient data Explorative Network, Odense University Hospital/Department of Clinical Research, University of Southern Denmark, Odense, Denmark

4. Centre for Public Health, Queen's University Belfast, Belfast, United Kingdom

\section{Corresponding author:}

Christina Doefler Poulsen, MD, PhD

Department of Ophthalmology

Odense University Hospital

Sdr. Boulevard 29

DK-5000 Odense C

Denmark

E-mail: christina.doefler.poulsen@rsyd.dk

Phone: +4565412782

Fax: +4565413004

\section{Key words:}

Rhegmatogenous retinal detachment; Surgery; Vitrectomy; Macula; Predictor; Visual function 


\section{ABSTRACT:}

\section{Purpose:}

To determine the long-term outcome of patients operated with pars plana vitrectomy (PPV) for primary rhegmatogenous retinal detachment (RRD) and to identify potential predictors for poor visual outcome.

\section{Methods:}

Prospective, observational 30-month study of patients operated for primary RRD with PPV. Examinations were performed preoperatively and after Month2, Month6, and Month30.

\section{Results:}

Eighty-four patients (84 eyes) were included and 73 (86.9\%) participated at Month30. Macula was attached in $30(35.7 \%)$ patients at primary operation.

Majority of patients $(\mathrm{n}=59,80.8 \%)$ achieved a good final best corrected visual acuity $(\mathrm{BCVA} \leq 0.3$ $\log$ MAR, $\geq 0.5$ Snellen $)$ with a better outcome in patients with macula attached than detached $(0.02$ $\log$ MAR versus $0.17 \log$ MAR, $\mathrm{P}=0.007)$.

Variables associated with poor visual outcome were baseline $\mathrm{BCVA}>0.3 \log \mathrm{MAR}(\mathrm{P}=0.03)$, female gender $(\mathrm{P}=0.02)$, silicone oil $(\mathrm{P}=0.03)$ and larger areas of retinal detachment $(\mathrm{P}=0.01)$. In multivariable regression analysis, female gender $(\mathrm{OR}=8.5(95 \% \mathrm{CI}: 1.8-39.8))$ was the strongest risk factor for poor visual outcome.

\section{Conclusion:}

Majority of patients operated for primary RRD achieved a reasonable long-term visual outcome. Notable, female gender was associated to poor visual outcome, indicating a need for closer followup. 


\section{Introduction:}

Rhegmatogenous retinal detachment (RRD) is an acute sight-threatening condition with an annual incidence of 20.7 (95\% CI 19.1-22.4) per 100,000 inhabitants above 15 years [1]. A recent Danish study demonstrated increasing RRD over the last decade, possibly due to a higher frequency of cataract surgeries, an aging population, and myopia [2-5].

The only treatment for RRD is surgical repair in order to restore the contact between the neuroretina and the retinal pigment epithelium (RPE). Surgical techniques have improved remarkably over the last decades with a final anatomical success rate of around $80 \%$ in the 1980 's [6] to nearly $100 \%$ in the last decade [7]. The two most common surgical techniques for RRD are internal surgery with pars plana vitrectomy (PPV) and external surgery with scleral buckling (SB). Both types of surgical techniques have been successful, but PPV has been increasingly popular world-wide [8-11], especially in pseudophakic patients $[10,12,13]$. Since the introduction of PPV by Machemer in 1972 [14], the technology has improved remarkably, and 25 gauge (G) PPV systems are some of the newest developments.

Silicone oil (SO) and gas are used as tamponades in PPV. In recent years the use of gas has increased [1] after several studies [15-17] have demonstrated visual impairment in eyes treated with SO. Other factors as macular involvement [12], pre-operative proliferative vitreoretinopathy (PVR) [18], extension of the RRD [18], time of macular detachment [19], and the age of the patient [12] have also been associated with poorer functional outcome.

Several studies have evaluated short-tem functional and anatomical outcome of primary RRD [12, 19, 20]. However, long-term studies are lacking. In this clinical study, we prospectively evaluated 1) the anatomical and functional outcome at 30 months after the primary operation, and 2) potential predictors for poor visual outcome.

\section{Methods:}

\section{Study design and patient population}

This was a prospective, observational, long-term study of patients operated for primary RRD at the Department of Ophthalmology, Odense University Hospital (OUH), Denmark, during $1^{\text {st }}$ of January 2013 and $12^{\text {th }}$ of July 2013. Patients younger than 15 years with RRD were referred to other Danish hospitals according to national recommendations. Patients were referred from the Region of 
Southern Denmark that includes 1.2 million of the total Danish population of approximately 5.7 million (Statistics Denmark 2016) [21] [21].

The study was conducted in accordance with the criteria of Helsinki II Declaration and in accordance with good epidemiological and clinical practice. Patients gave their written informed consent before their participation. The study was approved by the Research Ethics Committee of the Region of Southern Denmark and by the Danish Data Protection Agency.

\section{Baseline examinations}

Baseline examination was performed at admission by the attending ophthalmologist at the Department of Ophthalmology, OUH. Patients underwent standard eye examination, including best corrected visual acuity (BCVA) measured by standard Snellen chart at six meters with subjective refraction, intraocular pressure (IOP) (Goldmann applanation tonometry), slit-lamp biomicroscopy using the 90 diopter (D) lens and three-mirror lens. Additional examinations performed by the study investigator (CP) were auto refraction (Canon RK-2, Auto ref-keratometer, Amstelveen, The Netherlands), spectral domain optical coherence tomography (SD-OCT) (3D OCT-2000, Topcon, Tokyo, Japan), and Ultra-Widefield (UWF) imaging (Optos plc, Dunfermline, Scotland, United Kingdom). Examinations and imaging were performed after mydriatic eye drops were given (tropicamide 1\% and epinephrine 10\% in each eye). Radial SD-OCT scans were used to confirm whether macula was attached or detached at baseline. Surgical descriptions were used when macula could not be detected by SD-OCT and in cases where SD-OCT could not be captured. UWF-images were graded by the same trained grader $(\mathrm{CP})$, following a standardized protocol. Presence of proliferative vitreoretinopathy (PVR) was graded with use of the classification system defined by Machemer et al [22]: grade A (vitreous haze, pigment, vitreous cells and clumps), grade B (wrinkling of inner retinal surface, vessel tortuosity, rolled, irregular edge of tear), or grade C (full thickness retinal starfold). The extension of RRD was determined by the involved retinal quadrants on UWF imaging.

Presumed duration of macular detachment (partial/total) was defined as the time from significant loss of vision (defined by the patient) to primary RRD surgery. All examinations were performed as close to primary operation as possible.

Pre- and peroperative information 
Patients were allocated for operation as soon as possible and with respect to established local guidelines. Patients with attached macula were admitted to bed rest with allowance to restroom visits and to sit while eating. If patients were admitted during weekends or holidays they were operated on the first coming weekday. Patients with macula detached were sent home with information of minimal physical exertion until time of operation within a week but preferably as soon as possible.

Patients were operated with PPV using a standard 25G three-port system (Constellation, Alcon, Fort Worth, TX, USA). The tamponade used was SO (1000 centistoke) or gas (sulfur hexafluoride). Gas was the preference but SO was in general used in cases with inferior holes or tears or in severe or complicated cases. The vitreoretinal team of surgeons consisted of one experienced and four highly experienced retinal surgeons.

Peroperative data were collected using the surgical descriptions and the registered diagnosis-related grouping charge codes for surgical procedures.

\section{Follow-up examinations}

Follow-up examinations were all performed by the same investigator (CP) at Month 2, 6 and 30 . Examinations included a complete ophthalmologic examination with auto refraction, BCVA as measured by the Early Treatment Diabetic Retinopathy Study (ETDRS) scale, IOP, slit-lamp biomicroscopy with 90D lens, Pelli-Robson contrast sensitivity test (PR-CS) (Clement Clark International Ltd., Harlow Essex, United Kingdom), SD-OCT, and UWF imaging. The PR-CS was performed in the same room at a distance of one meter with standardized light $(60-120 \mathrm{~cd} / \mathrm{m} 2 \mathrm{or}$ 280 Lux). Distance correction was used, if necessary, with an addition of $+0.75 \mathrm{D}$ at 1.0 meter. The logarithmic contrast sensitivity value of the last line of which at least two of three letters were correctly seen was marked as the result. Complications or further operative procedures in the affected eye were registered at each follow-up exam. Anatomical success was defined as a fully attached retina at Month 30 in an eye without SO tamponade.

In addition to the study exams, patients were examined and treated as needed at the department or at private eye clinics.

\section{Data and statistical analyses}

Snellen and ETDRS values were converted to logMAR for statistical analysis using the base of the reciprocal of the Snellen fraction and a $0.02 \log$ MAR unit for each letter correctly read on the 
ETDRS chart [23]. We allocated the following logMAR values: counting fingers (CF) (logMAR = $2.5)$, hand movements $(\mathrm{HM})(\log \mathrm{MAR}=2.7)$ and light perception $(\log \mathrm{MAR}=3.0)$. We defined good VA as $\leq 0.3 \operatorname{logMAR}(\geq 0.5$ Snellen), and poor BCVA as $>0.3 \operatorname{LogMAR}(<0.5$ Snellen $)$. We defined incomplete data as patients with no follow-up examinations. Patients were stratified by macular status (attached versus detached) at baseline. Parametric data was expressed in mean (with SD) and non-parametric in median (with range). Differences in categorical data (sex, affected eye, age-group, myopia, BCVA (good/poor), lens status, tamponade, peeling, previous surgery, vitreous haemorrhage, location of RRD, PVR grade, macular status, duration of macular detachment) were analysed using the Chi-square test or Fisher's exact test for small samples. Differences in continuous data were analysed using Student-t test for normal distributed data (age, IOP, clock hours of detachment, BCVA, duration of operation) assuming equal variances in the groups. MannWhitney U-test was used for continuous data that were not normal distributed (number of holes and tears). Kruskal-Wallis was used for a three-way comparison of visual outcome. Univariate logistic regression analyses were performed to identify possible predictors for final BCVA $>0.3 \log$ MAR units. Due to the relatively small sample size, multiple logistic regression analysis only included age and variables statistically significantly associated with poor visual outcome in the univariate analysis. P-values $<0.05$ were considered as statistically significant. All statistics were calculated in STATA 13.0 (StataCorp, College Station, TX, USA).

\section{Results:}

\section{Inclusions and exclusions}

A total of 110 patients were examined for inclusion (Figure 1). We excluded non-surgically treated patients (for social or medical reasons, $n=3$ ), patients who were operated but declined to attend the study visits $(\mathrm{n}=7)$, patients with pre-existing retinal or macular pathology causing significant reduced vision $(\leq 0.5$ Snellen, $n=9)$, patients with previous eye trauma $(n=2)$ and patients with no follow-up $(\mathrm{n}=5)$.

Baseline characteristics were compared for patients included and excluded as well as for those attending the Month 30 examination versus those who dropped out during follow-up (Table 1). Excluded patients and patients who did not attend at the final follow-up were more likely to have macula detached at the time of the operation. In addition, non-attendees at Month 30 were older and more likely to be pseudophakic as compared to attendees (Table 1). 
Figure 1

Table 1

\section{Baseline characteristics}

We included 84 patients (84 eyes) for this study. Macula was attached in 30 (35.7\%) patients and detached in $54(64.3 \%)$ patients (Table 2). Mean age of included patients was 63.3 (SD 9.9) years, and did not differ $(\mathrm{P}=0.19)$ between men $(62.3 \pm 9.9$ years $)$ and women $(65.3 \pm 9.7$ years $)$. Baseline BCVA $>0.3 \log$ MAR was seen in $65.5 \%(n=36)$ of men versus $55.2 \%(n=16)$ of women, $(\mathrm{P}=0.36)$. Table 2 presents the baseline demographics and anatomical characteristics for included patients, and the univariate analysis for the differences between patients with macula attached and detached. Patients in the former group were more likely to be excessive myopic, have good baseline BCVA, and to have been operated with gas tamponade.

\section{Table 2}

\section{Anatomical characteristics of RRD}

Surgical description of macular status was used in three cases where macula could not be detected by SD-OCT (one patient with vitreous hemorrhage and two patients with bullous RRD) and in two cases where SD-OCT could not be captured. The median duration of macular detachment to primary RRD operation was four days with a range from 1 to 32 days. Univariate analysis showed that more patients with attached macula had vitreous hemorrhages or opacities at baseline $(\mathrm{P}=$ 0.003). On the other hand, patients with macula detached had larger areas of retinal detachment as well as more Grade B or C PVR $(\mathrm{P}<0.001$ and $\mathrm{P}=0.001$, respectively) (Table 2). A total of $60(71.4 \%)$ patients had detectable retinal breaks at baseline. In $24(28.6 \%)$ patients the break could not be identified by UWF-imaging or by slit-lamp biomicroscopy with 90-D and threemirror lens.

\section{Surgical procedures}

All primary operations were performed with minimal invasive 3-port 25-gange PPV and the use of either gas $(61.9 \%, \mathrm{n}=52)$ or SO $(38.1 \%, \mathrm{n}=32)$. More patients with PVR Grade B or C were 
treated with SO $(\mathrm{n}=25,43.1 \%)$, as compared to those with Grade A or no PVR $(n=7,26.9 \%)(\mathrm{P}=$ $0.16)$.

Primary RRD surgery with PPV and SO took longer to perform (108.1 minutes, SD 28.7 minutes) as compared to PPV with gas $(79.7$ minutes, SD 22.7 minutes, $\mathrm{P}<0.001)$. Median time from the primary operation to SO removal was 64 days ranging from 12 to 137 days. One patient had SO in situ at Month 30.

Peeling of internal limiting membrane (ILM) was performed in $92.9 \%(n=78)$ of primary operated eye, regardless of macular status (Table 2). Two of the six non-ILM peeled eyes developed epiretinal membrane (ERM) and underwent postoperative PPV with ILM-peeling.

One phakic patient had combined RRD and cataract surgery. At Month $30(n=73)$, nearly all patients who were phakic at baseline had undergone cataract surgery (42 of 43 patients, 98.6\%), and most of these $(90.5 \%, 38$ of 42$)$ were operated within 6 months from the primary RRD operation.

\section{Functional outcome}

A total of $80.8 \%(n=59)$ patients achieved a final BCVA $\leq 0.3 \log M A R$, and $38.3 \%(n=28)$ of these improved from baseline VA $>0.3 \log$ MAR. This was a statistical significant improvement $(\mathrm{P}$ $<0.001)$. The development of BCVA in relation to macular status at time of operation is presented in Figure 2. We found a statistically significant difference in the final median BCVA at Month30 in patients with macula attached and detached (0.02 logMAR (-0.20 to 1.66) versus $0.17 \log$ MAR (0.10 to 0.66$), \mathrm{P}=0.007)$.

Final median BCVA did not differ between patients who were phakic and pseudophakic at baseline (0.14 (-0.20 to 1.66$)$ vs $0.10(-0.20$ to 0.52$) \log$ MAR, $P=0.34)$, but patients treated with PPV and SO tamponade had significantly worse median BCVA at Month 30 as compared to those with gas $(0.19(-0.20$ to 1.18$)$ versus $0.08(-0.20$ to 1.66$) \log$ MAR, $\mathrm{p}=0.02)$.

The Pelli-Robson contrast sensitivity (PR-CS) test was performed at Month 2, 6 and 30. Patients with macula attached had better median PR-CS at Month 2 as compared to patients with macula detached (1.65 (1.35 to 1.95) versus 1.57 (0.45 to 1.8), $\mathrm{P}<0.001)$ At Month30, this difference was still statistically significant (1.65 (0.00 to 1.95$)$ versus 1.65 (1.05 to 1.80$)$ ), $\mathrm{P}=0.01)$. The final median VA at Month30 was $0.02 \operatorname{logMAR}(-0.2-1.66)$ in patients with macula attached, $0.14 \log$ MAR (-0.10 to 0.66$)$ in RRD with macula detached $\leq 8$ days $(\mathrm{n}=27)$ and $0.18 \log$ MAR (0.06 to 0.60$)$ in patients with macula detached $>8$ days $(\mathrm{n}=17)(\mathrm{P}=0.02$, Kruskal-Wallis $)$. 
Figure 3

\section{Complications and anatomical outcome}

In all, 7.1\% patients (6 of 84 patients) were re-operated due to re-detachment during the 30 the months of follow-up. Five of these had PVR Grade C at the time of the operation. Mean age for these patients was 64.4 (SD 9.8) years, and 33.3\% were males. One patient had good final BCVA $(0.32 \log$ MAR $)$ and five poor VA $(0.40 ; 0.66 ; 1.18 ; 1.66 \log$ AAR $)$ at Month 30 . Due to PVR and localized re-detachment in the inferior retina, one patient had SO in the eye at final follow-up. The remaining re-detachments were successful reattached after one (4 of $6,0.67 \%)$ and two reoperations ( 1 of $6,0.17 \%$ ), respectively. All re-detachments occurred no later than three months after the primary operation. The final anatomical success for Month 30 participants was $98.6 \%$ (72 of 73 patients).

High intraocular pressure (IOP $>22 \mathrm{mmHg}$ ) occurred within two months of follow-up in $46.4 \%$ ( $\mathrm{n}=$ 14 of 29) of patients treated with SO versus $13.3 \%$ ( 5 of 44$)$ of patients treated with gas $(p=0.002)$. Of these, $73.7 \%$ (gas, $\mathrm{n}=5$ versus $\mathrm{SO}, \mathrm{n}=9, \mathrm{P}=0.04$ ) had intraocular pressure reducing treatment at Month 2. At Month 30, all patients $(n=73)$ had normalized IOP, with a mean pressure of 14.6 $\mathrm{mmHg}(\mathrm{SD} \pm 2.6)$. However, $11.0 \%$ (gas, $\mathrm{n}=6$ versus $\mathrm{SO}, \mathrm{n}=2 ; \mathrm{P}=0.01$ ) of patients needed pressure reducing treatment to achieve this.

\section{Possible predictors for poor visual outcome}

We performed univariate logistic regression analysis of possible predictors for poor visual outcome at Month30. The factors significantly associated with a poor final BCVA $(>0.3 \log$ MAR at Month30) were poor baseline BCVA, female gender, retinal detachment $>6$ clock hours, and SO used as tamponade (Table 3).

In the multiple logistic regression analysis female gender and poor baseline BCVA $(>0.3 \log \mathrm{MAR})$ were the only factors predictive of poor final visual outcome $(\mathrm{OR}=8.5$ (95\% CI: $1.8-39.8)$ and $\mathrm{OR}=6.5(95 \% \mathrm{CI}: 1.1-41.1)$ (Table 3$)$. When comparing baseline data for men $(\mathrm{n}=36)$ and women $(\mathrm{n}=16)$ at Month30, we found no differences regarding age $(60.8 \pm 9.2$ years vs $64.0 \pm 9.5$ years, $\mathrm{P}=0.15)$, macula detachment (59.6\% vs $61.5 \%, \mathrm{P}=0.87)$, excessive myopia (31.9\% vs $23.1 \%, \mathrm{P}=0.42)$, $\mathrm{PVR}$ grade $\mathrm{B} / \mathrm{C}(74.5 \%$ vs $57.7 \%, \mathrm{P}=0.14)$ and baseline $\mathrm{BCVA}>0.3 \operatorname{logMAR}$ (54.4\% vs $59.2 \%, \mathrm{P}=0.68)$. However, there was a tendency towards more reoperations in women compared to men $(19.2 \%$ vs $6.4 \%, \mathrm{P}=0.09)$. 
Table 3

\section{Discussion:}

The present study reports the long-term outcomes of 25-G PPV in patients with primary RRD. We demonstrated a high rate of good anatomical outcome, even in patients with pre-operative PVR Grade $\mathrm{B} / \mathrm{C}$ and large area of detachment. Likewise, most patients also showed good functional outcome $(\leq 0.3 \log$ MAR $)$ regardless of lens and macular status prior to the operation. Factors associated with poor visual outcome were decreased baseline VA, female gender, the use of SO tamponade and more than six clock hours of retinal detachment. Surprisingly, female gender was the strongest predictor for poor visual outcome.

Patients were operated with PPV with either SO or gas regardless of lens status or RRD severity. This approach is debatable since more studies [24], including the prospective, randomized multicenter SPR-Study by Heimann et al, have recommended scleral buckling procedure to phakic patients and uncomplicated RRD, due to better postoperative visual outcome [8].

Our study showed no difference in median visual outcome at Month30 between phakic and pseudophakic patients. Even though there was a difference according to macular attachment or detachment, the median visual outcome was good in both groups. The final visual outcome for phakic or pseudophakic patients and patients with either macula attached or detached was, either comparable or slightly better, as compared to results in previous studies $[8,10,12,19]$. However, the follow-up period in these studies varied between 3 to 12 months compared to 30 month in the present study. Furthermore, comparisons of results with other studies are difficult because of the differences in the study designs, patients and surgical procedures for RRD [19].

Predictors for poor visual outcome have previously included age [12], area of retinal detachment $[12,25]$, pre-operative BCVA [26], pre-operative PVR [12, 25], previous ocular surgery [12] and macular status $[12,25]$. In agreement with previous results, multiple logistic regression showed that poor baseline BCVA was an independent predictor for poor visual outcome. Surprisingly, female gender was the strongest risk factor with a risk of 8.5 times as compared to male. Female gender has previously been associated with worse anatomical outcome [27] but as far as we are aware, not with poor functional outcome. We found a tendency towards a higher reoperation rate in women. This may explain the worse outcome in women, but future studies on the current topic are recommended. 
In univariate analysis, SO and detachment $>6$ clock hours were all associated with poor visual outcomes, but in the multiple logistic regression model these associations disappeared. On this issue our long-term results differ from shorter-term studies that have consistently demonstrated associations between SO tamponade and postoperative vision loss [15, 16, 28].

We found a high final anatomical success rate. This was in accordance with previous studies evaluating the use of $25 \mathrm{G}$ PPV [29, 30]. However, with regard to the used tamponade, we found a rather frequently use of SO as compared to other countries [10,25]. Silicone oil has previously been shown as the primary used tamponade for complicated RRD, especially in cases with inferior PVR [31,32]. Our results support these findings, as eyes with more severe grades of PVR (B or C) were more frequently operated with PPV and the use of SO as compared to eyes with no PVR or Grade A PVR. The presence of higher levels of PVR may also explain the frequently use of SO and the longer duration of operations with PPV and SO compared to PPV with gas.

A common complication to RRD with PPV is ERM. To prevent this, nearly all included eyes underwent primary PPV with peeling of ILM, regardless of macular status. None of the ILM peeled eyes developed ERM during the 30 months follow-up, whereas two of the six (33.3\%) non-ILM peeled eyes developed ERM. Due to the small sample size we are not able to report the long-term visual outcome in non-ILM peeled eyes. However, ILM-peeled eyes have good final mean VA at Month30. These results are comparable to a recent retrospective study by Nam KY and Kim JY, who found that none of the ILM peeled eyes developed ERM and that ILM peeled eyes with macula attached had better visual outcome as compared to none-ILM peeled eyes with macula attached [33]. They concluded that ILM peeling seemed to prevent the development of post-operative ERM in patients with primary RRD. Our study results support this statement.

At Month 30, nearly all patients who were phakic at baseline had undergone cataract surgery, and most of these were operated within 6 months from primary RRD operation. This result was in alignment with findings by Nam KY and Kim JY [33] but higher than results from the larger retrospective study by Heimann et al. and the prospective study by Mitry et al. [19, 25]. This variation in results may be influenced by differences in study designs and surgical procedures for RRD.

Complications as increased IOP within two months from primary operation were detected in near half of patients treated with SO tamponade. This frequency was higher than for those treated with PPV and gas tamponade. At Month30 IOP had normalized, although sometimes assisted by 
pressure reducing treatment. Elevation of IOP is a known complication to PPV and especially with use of SO tamponade [29, 32]

With an attendance of $87 \%$ at Month 30 this study is able to present important information of the long-term outcomes of 25-G PPV in both phakic and pseudophakic patients with RRD. However, it is also important to acknowledge limitations like the observational design and the relatively small sample size. Furthermore, a comparison of results with other studies was difficult because of differences in study designs, patients and surgical procedures for RRD.

In a long-term follow-up of patients with primary RRD, we found a good anatomical and functional outcome, regardless of lens status and macular status at the time of primary operation. A surprise of this study was the finding of female gender as a strong predictor for poor visual outcome.

Our results suggest that 25-G PPV can be used as first choice of treatment for primary RRD, and that women may benefit from closer follow-up.

\section{Acknowledgment:}

Parts of the included data has previous been presented as a poster and abstract at the Nordic Congress of Ophthalmology 2016, Aarhus, Denmark.

\section{Statement of Ethics}

This study was approved by the Danish Data Protection Agency and the Research Ethics Committee of the Region of Southern Denmark. All parts of the study were conducted in accordance with the Helsinki declaration II and in accordance with good clinical practice.

\section{Data availability:}

Data available at the discretion of the authors.

\section{Conflicts of interests:}

The authors declare that there is no conflict of interest regarding the publication of this paper.

\section{Author Contributions}

CDP, JG, TP and AG contributed to the concept and design of the study. CDP contributed to the acquisition of data. Data analyses were performed by CDP, who also wrote the initial draft of the 
paper. AG, JG and TP revised the paper critically for intellectual content. All authors approved the final version of the paper.

\section{Funding statement:}

Alice Rasmussen Memorial Fund, The Foundation of A. P. Møller and Chastine Mc-Kinney Møller, The Research Grant at the University of Southern Denmark, Director Jakob Madsen and Wife Olga Madsen Foundation, King Christian the X Foundation, Henry and Astrid Møller's Foundation, A.J. Andersen and Wife Foundation, Einar Willumsen's Memorial Fund, Department of Clinical Research Foundation at Odense University Hospital, The Region of Southern Denmark, and The Department of Clinical Research at University of Southern Denmark. 


\section{References:}

1. Poulsen, C.D., et al., Epidemiologic characteristics of retinal detachment surgery at a specialized unit in Denmark. Acta Ophthalmol, 2016.

2. Hajari, J.N., et al., A nationwide study on the incidence of rhegmatogenous retinal detachment in Denmark, with emphasis on the risk of the fellow eye. Retina, 2014. 34(8): p. 1658-65.

3. Morgan, I.G., K. Ohno-Matsui, and S.M. Saw, Myopia. Lancet, 2012. 379(9827): p. 173948.

4. Mitry, D., et al., The epidemiology of rhegmatogenous retinal detachment: geographical variation and clinical associations. Br J Ophthalmol, 2010. 94(6): p. 678-84.

5. Park, S.J., et al., Five year nationwide incidence of rhegmatogenous retinal detachment requiring surgery in Korea. PLoS One, 2013. 8(11): p. e80174.

6. $\quad$ Escoffery, R.F., et al., Vitrectomy without scleral buckling for primary rhegmatogenous retinal detachment. Am J Ophthalmol, 1985. 99(3): p. 275-81.

7. Heimann, H., et al., [Primary pars plana vitrectomy. Techniques, indications, and results]. Ophthalmologe, 2008. 105(1): p. 19-26.

8. Heimann, H., et al., Scleral buckling versus primary vitrectomy in rhegmatogenous retinal detachment: a prospective randomized multicenter clinical study. Ophthalmology, 2007. 114(12): p. 2142-54.

9. de la Rua, E.R., et al., Non-complicated retinal detachment management: variations in 4 years. Retina 1 project; report 1. Br J Ophthalmol, 2008. 92(4): p. 523-5.

10. Falkner-Radler, C.I., et al., Trends in primary retinal detachment surgery: results of a Bicenter study. Retina, 2011. 31(5): p. 928-36. 
11. Lehpamer, B.P. and P.E. Carvounis, Vitrectomy with and without scleral buckling for retinal detachment repair in pseudophakic patients. Int Ophthalmol Clin, 2014. 54(2): p. 79-90.

12. Pastor, J.C., et al., Surgical outcomes for primary rhegmatogenous retinal detachments in phakic and pseudophakic patients: the Retina 1 Project--report 2. Br J Ophthalmol, 2008. 92(3): p. 378-82.

13. Sharma, Y.R., et al., Functional and anatomic outcome of scleral buckling versus primary vitrectomy in pseudophakic retinal detachment. Acta Ophthalmol Scand, 2005. 83(3): p. 293-7.

14. Machemer, R., J.M. Parel, and E.W. Norton, Vitrectomy: a pars plana approach. Technical improvements and further results. Trans Am Acad Ophthalmol Otolaryngol, 1972. 76(2): p. 462-6.

15. la Cour, M., A. Lux, and S. Heegaard, [Visual loss under silicone oil]. Klin Monbl Augenheilkd, 2010. 227(3): p. 181-4.

16. Newsom, R.S., et al., Sudden visual loss after removal of silicone oil. Retina, 2004. 24(6): p. $871-7$.

17. Williams, P.D., et al., Vision loss associated with the use and removal of intraocular silicone oil. Clin Ophthalmol, 2008. 2(4): p. 955-9.

18. Mitry, D., et al., Surgical outcome and risk stratification for primary retinal detachment repair: results from the Scottish Retinal Detachment study. Br J Ophthalmol, 2012. 96(5): p. $730-4$.

19. Mitry, D., et al., Long-term visual acuity and the duration of macular detachment: findings from a prospective population-based study. Br J Ophthalmol, 2013. 97(2): p. 149-52. 
20. Gerding, H. and A. Hersener, Anatomical and functional results of primary pars plana vitrectomy in rhegmatogenous retinal detachment. Klin Monbl Augenheilkd, 2013. 230(4): p. 409-12.

21. Statistics Denmark (2016): http://www.statbank.dk/FOLK1A Accessed 16-8-2016.

22. Machemer, R., et al., An updated classification of retinal detachment with proliferative vitreoretinopathy. Am J Ophthalmol, 1991. 112(2): p. 159-65.

23. Ferris, F.L., 3rd, et al., New visual acuity charts for clinical research. Am J Ophthalmol, 1982. 94(1): p. 91-6.

24. Sun, Q., et al., Primary vitrectomy versus scleral buckling for the treatment of rhegmatogenous retinal detachment: a meta-analysis of randomized controlled clinical trials. Curr Eye Res, 2012. 37(6): p. 492-9.

25. Heimann, H., et al., Primary vitrectomy for rhegmatogenous retinal detachment: an analysis of 512 cases. Graefes Arch Clin Exp Ophthalmol, 2006. 244(1): p. 69-78.

26. Oshima, Y., et al., Two-year follow-up study comparing primary vitrectomy with scleral buckling for macula-off rhegmatogenous retinal detachment. Jpn J Ophthalmol, 2000. 44(5): p. 538-49.

27. Halberstadt, M., et al., Analysis of risk factors for the outcome of primary retinal reattachment surgery in phakic and pseudophakic eyes. Klin Monbl Augenheilkd, 2003. 220(3): p. 116-21.

28. Christensen, U.C. and M. la Cour, Visual loss after use of intraocular silicone oil associated with thinning of inner retinal layers. Acta Ophthalmol, 2012. 90(8): p. 733-7.

29. Susskind, D., et al., Primary vitrectomy for rhegmatogenous retinal detachment in pseudophakic eyes: 20-gauge versus 25-gauge vitrectomy. Acta Ophthalmol, 2016. 
30. Bourla, D.H., et al., Outcomes and complications of rhegmatogenous retinal detachment repair with selective sutureless 25-gauge pars plana vitrectomy. Am J Ophthalmol, 2010. 149(4): p. 630-634.e1.

31. Joussen, A.M., et al., Heavy silicone oil versus standard silicone oil in as vitreous tamponade in inferior PVR (HSO Study): interim analysis. Acta Ophthalmol, 2011. 89(6): p. e483-9.

32. Heimann, H., T. Stappler, and D. Wong, Heavy tamponade 1: a review of indications, use, and complications. Eye (Lond), 2008. 22(10): p. 1342-59.

33. Nam, K.Y. and J.Y. Kim, Effect of internal limiting membrane peeling on the development of epiretinal membrane after pars plana vitrectomy for primary rhegmatogenous retinal detachment. Retina, 2015. 35(5): p. 880-5. 
Figure 1: Flowchart illustrating the flow of patients through the study.

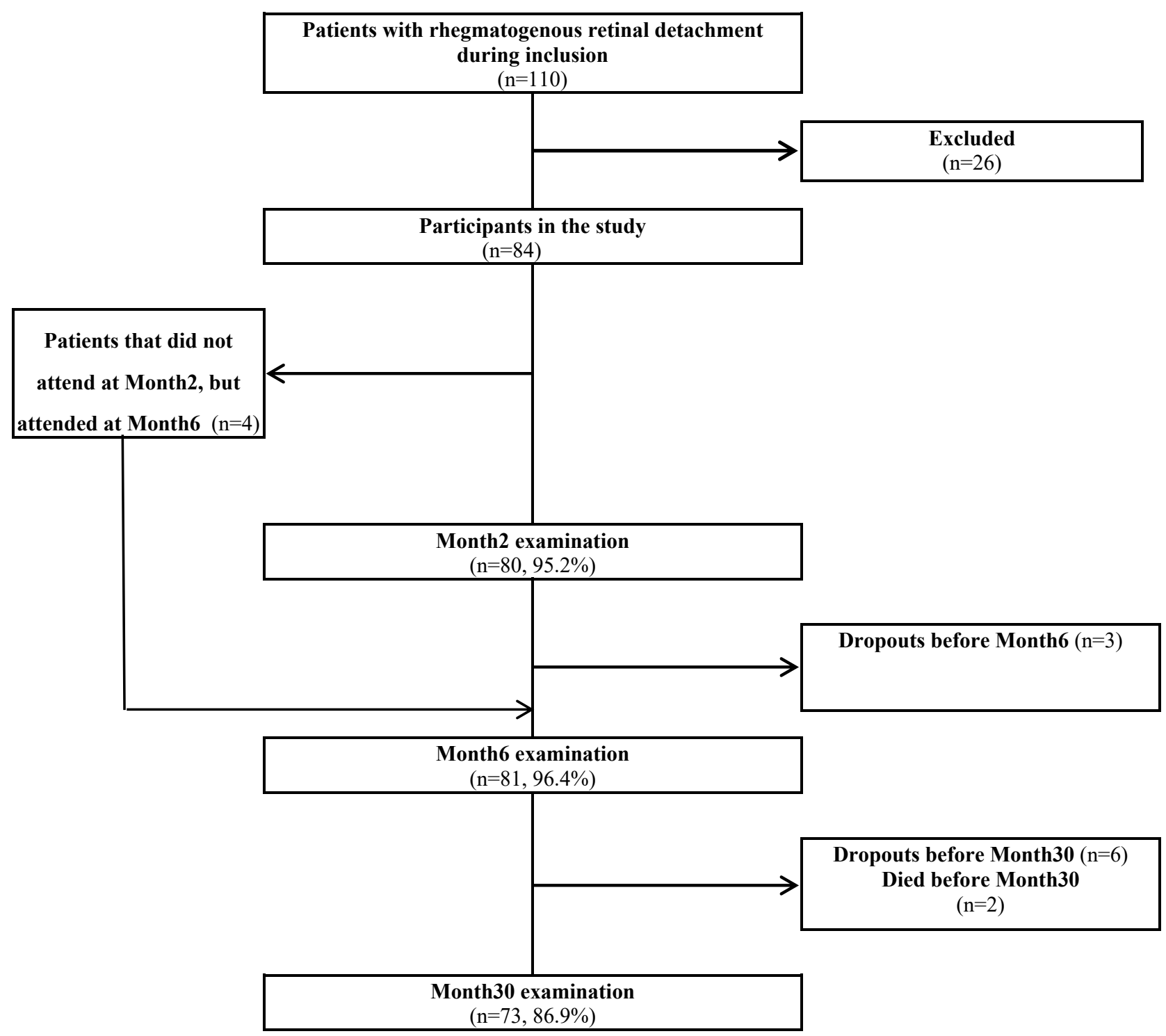


Figure 2: Illustration of the median (logMAR) visual acuity (VA) for each visit, according to macular status at time of operation.

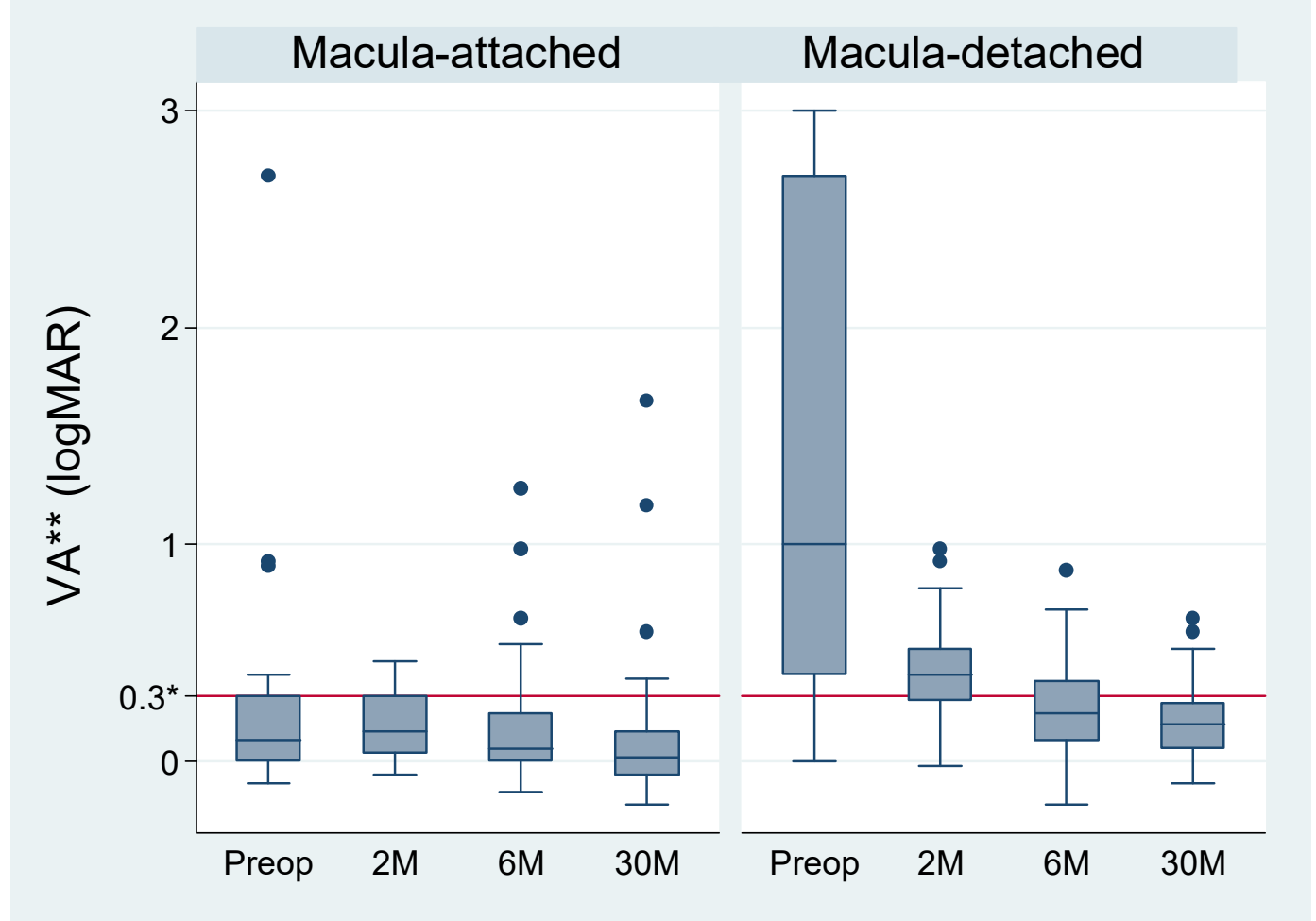

*Good visual acuity $\leq 0.3 \log$ MAR ( $\geq 0.5$ Snellen)

** LogMAR: $2.5=$ counting fingers; $2.7=$ hand movements; $3.0=$ light perception 
Table 1 Baseline demographics and univariate analysis for included versus excluded patients, and Month30 patients versus non-participants at Month30 (dropouts).

\begin{tabular}{lcccccc}
\hline & $\begin{array}{c}\text { Included } \\
(\mathrm{n}=84)\end{array}$ & $\begin{array}{c}\text { Excluded } \\
(\mathrm{n}=26)\end{array}$ & P-value & $\begin{array}{c}\text { Month30 } \\
(\mathrm{n}=73)\end{array}$ & $\begin{array}{c}\text { Dropout: }_{(\mathrm{n}=11)} \\
\text { P-value }\end{array}$ \\
\hline Age, years (SD) & $63.3(9.9)$ & $58.5(19.0)$ & 0.08 & $61.9(9.2)$ & 72.8 & $\mathbf{0 . 0 0 4}$ \\
& & & & & $(9.2)$ & \\
Male, \% & 65.5 & 73.1 & 0.69 & 64.4 & 72.7 & 0.74 \\
Phakic, \% & 57.1 & 38.5 & 0.48 & 42.5 & 27.3 & 0.06 \\
Gas tamponade, \% & 61.9 & 43.5 & 0.09 & 64.4 & 45.5 & 0.23 \\
Macula detached, \% & 64.3 & 88.5 & $\mathbf{0 . 0 0 5}$ & 58.3 & 90.9 & $\mathbf{0 . 0 2}$ \\
\hline
\end{tabular}

${ }^{a}$ Significant difference: $\mathrm{P}<0.001$ (marked) 
Table 2: Baseline demographics and anatomical characteristics for all included patients and stratified according to macular status

\begin{tabular}{|c|c|c|c|c|}
\hline Variable & $\begin{array}{c}\begin{array}{c}\text { Total } \\
N=84 \\
(100.0 \%)\end{array}\end{array}$ & $\begin{array}{c}\text { Macula } \\
\text { attached } \\
\mathrm{N}=30(35.7 \%)\end{array}$ & $\begin{array}{c}\text { Macula } \\
\text { detached } \\
\mathrm{N}=54(64.3 \%)\end{array}$ & P-value* \\
\hline Sex, n (\%) & & & & 0.86 \\
\hline Male & $55(65.5)$ & $20(66.7)$ & $35(64.8)$ & \\
\hline Female & $29(34.5)$ & $10(33.3)$ & $19(35.2)$ & \\
\hline Affected Eye, n (\%) & & & & 0.22 \\
\hline Right & $40(47.6)$ & $17(56.7)$ & $23(42.6)$ & \\
\hline Left & $44(52.4)$ & $13(43.3)$ & $31(57.4)$ & \\
\hline Age Group, n (\%) & & & & 0.74 \\
\hline$<40$ years & $2(2.4)$ & $1(3.3)$ & $1(1.9)$ & \\
\hline $40-59$ years & $29(34.5)$ & $11(36.7)$ & $18(33.3)$ & \\
\hline $60-79$ years & $50(59.5)$ & $18(60.0)$ & $32(59.3)$ & \\
\hline$>80$ years & $3(3.6)$ & $0(0.0)$ & $3(5.6)$ & \\
\hline Excessive myopia ( $\geq-5$ D), n (\%) & $22(26.28)$ & $13(43.3)$ & 9 (16.7) & 0.008 \\
\hline BCVA, n (\%) & & & & $<0.001$ \\
\hline Good ( $\leq 0.3 \log M A R)$ & $32(38.1)$ & $24(80.0)$ & $8(14.8)$ & \\
\hline Poor (> 0.3 logMAR) & 52 (61.9) & $6(20.0)$ & $46(85.2)$ & \\
\hline $\begin{array}{l}\text { High intraocular pressure, mean } \\
\text { (SD) }\end{array}$ & $13.7( \pm 3.8)$ & $13.9( \pm 3.8)$ & $13.6( \pm 3.3)$ & 0.77 \\
\hline Pre-operative lens status, n (\%) & & & & 0.32 \\
\hline Phakic & $48(57.1)$ & $15(50.0)$ & $33(61.1)$ & \\
\hline Pseudophakic & $36(42.9)$ & $15(50)$ & $21(38.9)$ & \\
\hline Tamponade, n (\%) & & & & 0.01 \\
\hline Gas & $52(61.9)$ & $24(80.0)$ & $28(51.9)$ & \\
\hline Silicone oil & $32(38.1)$ & $6(20.0)$ & $26(48.2)$ & \\
\hline Peeling of ILM, n (\%) & 78 (92.9) & $30(45.7)$ & $54(64.3)$ & 0.18 \\
\hline Previous PPV on affected eye, $n(\%)$ & $4(4.8)$ & $1(25.0)$ & $3(85.0)$ & 0.64 \\
\hline Vitreous hemorrhage/opacity, n (\%) & $18(21.4)$ & $13(72.2)$ & $5(27.8)$ & 0.003 \\
\hline Location of RD, n (\%) & & & & 0.31 \\
\hline Superior quadrants & $19(23.2)$ & 11 (57.9) & $8(42.1)$ & \\
\hline Inferior quadrants & $11(13.4)$ & $4(36.4)$ & $7(63.6)$ & \\
\hline $\begin{array}{l}\text { Both inferior and superior } \\
\text { quadrants }\end{array}$ & $52(63.4)$ & $19(36.5)$ & $33(63.5)$ & \\
\hline PVR stage B or C, n (\%) & $58(69.0)$ & $14(24.1)$ & 44 (75.9) & 0.001 \\
\hline $\begin{array}{l}\text { Area of RRD (clock hours), } \\
\text { mean(SD) }\end{array}$ & $5.3( \pm 2.3)$ & $3.7( \pm 1.8)$ & $6.2( \pm 6.6)$ & $<0.001$ \\
\hline Number of holes, median (Range) & $1(1-11)$ & $1(1-2)$ & $2(1-11)$ & 0.06 \\
\hline Number of tears, median (Range) & $1(1-5)$ & $1(1-2)$ & $1(1-5)$ & 0.12 \\
\hline
\end{tabular}

$\mathrm{D}=$ diopters; ILM = intern limiting membrane; $\mathrm{N}=$ No. of cases; PPV = pars plana vitrectomy; $\mathrm{RD}=$ retinal detachment.

*A P-value $\leq 0.05$ was considered statically significant (marked). 
Table 3 Analysis of possible predictors for poor visual acuity $>0.3 \log$ MAR at Month30

\begin{tabular}{|c|c|c|c|c|c|c|}
\hline \multirow[b]{2}{*}{ Variable } & \multicolumn{3}{|c|}{$\begin{array}{c}\text { Univariate } \\
\text { logistic regression }\end{array}$} & \multicolumn{3}{|c|}{$\begin{array}{l}\text { Multiple logistic } \\
\text { regression }\end{array}$} \\
\hline & $\begin{array}{l}\text { Odds } \\
\text { Ratio }^{1}\end{array}$ & $\begin{array}{c}95 \% \\
\mathrm{Cl}\end{array}$ & $\begin{array}{c}\mathrm{P}- \\
\text { value* }\end{array}$ & $\begin{array}{l}\text { Odds } \\
\text { Ratio }\end{array}$ & $\begin{array}{c}95 \% \\
\mathrm{Cl}\end{array}$ & $\begin{array}{c}\mathrm{P}- \\
\text { value* }\end{array}$ \\
\hline Sex, female vs. male & 4.5 & $1.3-15.2$ & 0.02 & 8.5 & $1.8-39.8$ & 0.007 \\
\hline Baseline VA >0.3 logMAR vs. VA $\leq 0.3 \log M A R$ & 5.8 & $1.2-28.2$ & 0.03 & 6.6 & $1.1-41.1$ & 0.04 \\
\hline Tamponade, silicone oil vs. gas & 3.8 & $1.1-12.9$ & 0.03 & 2.3 & $0.5-9.8$ & 0.27 \\
\hline Detachment, $>6$ clock hours vs. $\leq 6$ hours & 4.3 & $1.4-12.9$ & 0.01 & 2.9 & $0.7-12.5$ & 0.16 \\
\hline Age at operation, per year & 1.1 & $1.0-1.1$ & 0.13 & 1.0 & $1.0-1.1$ & 0.74 \\
\hline Baseline myopia, $<-5$ dioptri vs. $\geq 5$ dioptri & 0.4 & $0.1-1.7$ & 0.20 & 1 & 1 & 1 \\
\hline Baseline lens status, pseudophakic vs. phakic & 0.8 & $0.2-2.5$ & 0.65 & 1 & 1 & 1 \\
\hline Baseline PVR, grade B/C vs. Non/Grade A & 0.8 & $0.2-2.7$ & 0.71 & 1 & 1 & 1 \\
\hline $\begin{array}{l}\text { Duration, macula detached } \leq 8 \text { days vs macula } \\
\text { attached }\end{array}$ & 1.3 & $0.3-5.5$ & 0.72 & 1 & 1 & 1 \\
\hline $\begin{array}{l}\text { Duration, macula detached }>8 \text { days vs macula } \\
\text { attached }\end{array}$ & 2.5 & $0.6-11.1$ & 0.23 & 1 & 1 & 1 \\
\hline Macula status at operation, detached vs. attached & 1.8 & $0.5-6.5$ & 0.35 & 1 & 1 & 1 \\
\hline Postoperative IOP, $>22 \mathrm{mmHg}$ vs. $\leq 22 \mathrm{mmHg}$ & 2.7 & $0.8-9.0$ & 0.12 & 1 & । & 1 \\
\hline
\end{tabular}

${ }^{*}$ A P-value $\leq 0.05$ was considered statistically significant.

** Due to the relatively small sample size, multiple logistic regression analysis only included age and variables significantly associated with poor visual outcome in the univariate analysis.

'Sample size too small for more analyze 